\title{
Substituted Geminal Dithienyltetrahydrofurans via an Intramolecular Williamson Reaction
}

\author{
Ursula Sonnewald \\ Laboratory of Medicinal Chemistry I, NOVO Research Institute, DK-2880 Bagsværd, Denmark
}

Sonnewald, U., 1988. Substituted Geminal Dithienyltetrahydrofurans via an
Intramolecular Williamson Reaction. - Acta Chem. Scand., Ser. B 42: 567-568.

Substituted dithienylbutenes were first prepared by Kleeman et al. ${ }^{1}$ who described the synthesis of 3-bromo-1,1-bis(3-thienyl)-1-propene. In our laboratory a similar reaction was carried out with 2-lithio-5-methylthiophene and ethyl 4-bromobutyrate (Scheme 1) and it was observed that the nature of the reaction product was dependent upon the reaction temperature. When the temperature was kept below ca. $10^{\circ} \mathrm{C}$ the expected product (1) was formed after the reaction had been quenched with water. When the reaction mixture was allowed to reach room temperature 2,2-bis(5-methyl-2-thienyl)tetrahydrofuran was obtained. The formation of $\mathbf{2}$ is probably due to the increased reactivity of the alkoxide at room temperature and the intramolecular nature of this Williamson reaction.

The same procedure, when used for other lithiothiophenes, also yields tetrahydrofurans, thus the method has generally application. Table 1

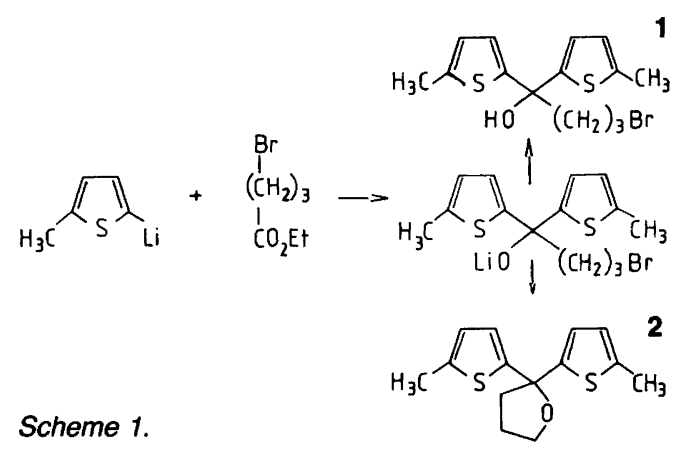

Acta Chemica Scandinavica B 42 (1988) 567-568 shows some tetrahydrofurans which were prepared using the appropriate starting materials.

Asymmetrically substituted dithienyl compounds can be prepared by treating 2-(4-chlorobutyryl)thiophene with 2-thienyllithium. The yields are not as high as those in the reactions described above owing to the considerable amount of cyclopropyl 2-thienyl ketone formed. Thus 2-(3-bromo-2-thienyl)-2-(2-thienyl)tetrahydrofuran (6) was prepared in $34 \%$ yield.

The above-mentioned tetrahydrofurans have been used to introduce other functional groups into the thiophene ring. 2,2-Bis(2-thienyl)tetrahydrofuran has been nitrated with nitric acid in acetic anhydride ${ }^{2}$ to yield 2,2-bis(5-nitro-2-thienyl)tetrahydrofuran (7) in $68 \%$ yield. The position of the nitro groups was determined by nuclear Overhauser experiments.

2,2-Bis(3-bromo-2-thienyl)tetrahydrofuran (4) has been treated with $\mathrm{CuCl}-\mathrm{DMF}^{3}$ to yield 2,2bis(3-chloro-2-thienyl)tetrahydrofuran (8). Compound 4 has also been converted into the lithium derivative ${ }^{4}$ with $\mathrm{BuLi}-\mathrm{Et}_{2} \mathrm{O}-70^{\circ} \mathrm{C}$ which was then allowed to react with acetaldehyde. The resulting 2,2-bis-[3-(1-hydroxyethyl)-2-thienyl]tetrahydrofuran was oxidized with pyridinium chlorochromate- $\mathrm{CH}_{2} \mathrm{Cl}_{2}{ }^{5}$ to the corresponding ketone (9) in $87 \%$ overall yield. The asymmetric compound (6) has been converted into the azide ${ }^{6} 10$ using $\mathrm{BuLi}-\mathrm{Et}_{2} \mathrm{O} ;-65^{\circ} \mathrm{C}$-dry ice-aq. $\mathrm{HCl}$. All compounds showed satisfactory microanalyses and NMR spectra. Most of the dithienyltetrahydrofurans underwent ring opening to the corresponding butenols (Scheme 2). 
SHORT COMMUNICATION

Table 1. Novel tetrahydrofurans ${ }^{a}$ prepared from the appropriate starting materials.

\begin{tabular}{llll}
\hline & Compound & M.P./ ${ }^{\circ} \mathrm{C}$ & Yield/\% \\
\hline 3 & 2,2-Bis(5-bromo-2-thienyl)- & 82 & 68 \\
4 & 2,2-Bis(3-bromo-2-thienyl)- & $88-92$ & 60 \\
5 & 2,2-Bis(2-thienyl)- & $45-46$ & 70 \\
\hline
\end{tabular}

${ }^{a}$ All compounds showed satisfactory microanalyses and NMR spectra.

\section{Experimental}

NMR spectra were recorded on a Bruker WM-400 spectrometer.

In a typical experiment 2.2 equiv. of butyllithium ( $2.5 \mathrm{~mol}^{-1}$ in hexane) and diethyl ether were cooled to $-65^{\circ} \mathrm{C}$ and 2 equiv. of 2-methylthiophene in diethyl ether were added slowly. After $1 \mathrm{~h}$ at $-65^{\circ} \mathrm{C}, 1$ equiv. of ethyl 4-bromobutyrate in diethyl ether was added and the reaction mixture was kept at $-65^{\circ} \mathrm{C}$ for $3 \mathrm{~h}$. Quenching the reaction at $-10^{\circ} \mathrm{C}$ with water and subsequent extraction with diethyl ether yielded 1 in $97 \%$ yield. When the reaction mixture was kept at room temperature overnight and then treated with water, 2 was formed in $85 \%$ yield and showed the following chemical shifts: ${ }^{1} \mathrm{H}$ NMR $\left(400 \mathrm{MHz} ; \mathrm{CDCl}_{3}\right): 2.02(2 \mathrm{H}$, quintet, $J 8 \mathrm{~Hz})$, $2.39(6 \mathrm{H}, \mathrm{s}), 2.50(2 \mathrm{H}, \mathrm{t}, J 8 \mathrm{~Hz}), 652(2 \mathrm{H}, \mathrm{d}, J$ $4 \mathrm{~Hz}), 6.65(2 \mathrm{H}, \mathrm{d}, J 4 \mathrm{~Hz})$.

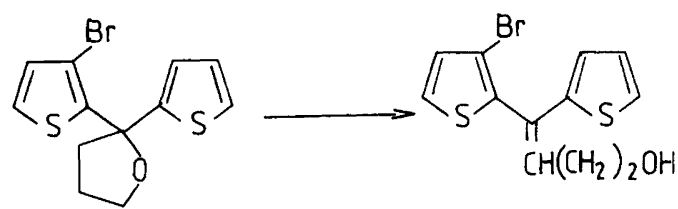

Scheme 2.

Tetrahydrofuran ring-opening reaction. In a typical experiment $10 \mathrm{mmol}$ of dithienyltetrahydrofuran were dissolved in $70 \mathrm{ml}$ of isopropyl alcohol and $10 \mathrm{ml}$ of concentrated aqueous $\mathrm{HCl}$ on a steam bath. The solution was kept on the steam bath until the starting material has been consumed, as indicated by TLC. The desired butenols were recovered as oils in high yields.

Acknowledgements. The author thanks Helle Brønnum for excellent technical assistance and Drs. Steffen B. Petersen and Henning Thøgersen for help with structure determinations.

\section{References}

1. Kleeman, A., Heese, J. and Engel, J. Drug Research, 31 (1981) 1178.

2. Sice, J. J. Am. Chem. Soc., 75 (1953) 3697.

3. Conde, S., Corral, C., Madronero, R. and Sanches Alvares-Insua, A. Synthesis (1970) 421.

4. Gronowitz, S. Ark. Kemi, 7 (1955) 100.

5. Corey, E. J. Tetrahedron Lett. (1979) 399

6. Spagnolo, P., Zanirato, P. and Gronovitz, S. J. Org. Chem., 47 (1982) 3177.

Received May 12, 1988. 